\title{
Organic-Inorganic Hybrid Composites as an Electron Injection Layer in Highly Efficient Inverted Green-Emitting Polymer
}

\section{LEDs}

Iain Hamilton', Minwon Suh', Kyungmok Kim², Duk Young Jeon ${ }^{2}$, Donal D. C. Bradley ${ }^{3 .}$ and JiSeon Kims,

1 Department of Physics \& Centre for Plastic Electronics, Imperial College London, Prince Consort Road, London SW7 2AZ, United Kingdom

2 Department of Materials Science and Engineering, Korea Advanced Institute of Science and Technology (KAIST), 291 Daehak-ro, Yuseong-gu, Daejeon 305-701, Republic of Korea

3 Departments of Physics and Engineering Science and Division of Mathematical, Physical and Life Sciences, University of Oxford, 9 Parks Road, Oxford, OX1 3PD, UK

4 Vice President for Research, PO Box 2000, King Abdullah University of Science and Technology (KAUST), Thuwal, 23955-6900, Saudi Arabia

* Corresponding author: ji-seon.kim@imperial.ac.uk

KEYWORDS: Hybrid light-emitting diodes, conjugated polyelectrolytes, zinc oxide, nanoparticles, electron injection layers, inverted 


\section{ABSTRACT}

Organic-inorganic hybrid light emitting diodes (HyLEDs) consist of an organic emission layer in combination with at least one metal oxide charge injection layer in an inverted structure. Low temperature, solution processing of metal oxide charge injection layers is one of the key factors in reducing the manufacture cost of HyLEDs. Herein, we report the use of composite materials, comprising conjugated polyelectrolytes (CPE) and zinc oxide nanoparticles (ZnO NPs), as the electron injection layer (EIL) in highly-efficient, green-light-emitting poly(9,9-dioctylfluorene-cobenzothiadiazole) (F8BT) polymer LEDs that are carefully optimised for use in an inverted HyLED architecture for the first time. The composite CPE:ZnO EILs are processed via a room temperature, one-step, solution deposition and enable superior device performance relative to $\mathrm{ZnO}$ NPs on their own. We find that specifically, they (i) improve EIL morphology, reducing surface roughness as well as pin-hole size and density, (ii) induce a favourable vacuum level shift for electron injection by coordinate bonding between the $\mathrm{CPE}$ and $\mathrm{ZnO}$ constituents, and (iii) reduce interfacial quenching by passivation of $\mathrm{ZnO}$ chemical defects caused by oxygen vacancies. This work is also the first demonstration that blending ZnO NPs and CPE supports much faster electroluminescence turn-on times $(\sim 7.12 \mu \mathrm{s})$ than for traditional $\mathrm{ZnO} / \mathrm{CPE}$ bilayer devices $(\sim 0.4$ s) via 'locking' of the CPE mobile ions, as well as higher device performance. This demonstrates good suitability for display applications. After optimisation of the EIL composition and the thickness of the F8BT emissive layer, we achieve promising device efficiencies of $16.5 \mathrm{~cd} / \mathrm{A}$ and $5.41 \mathrm{~lm} / \mathrm{W}$ for devices with a $1.1 \mu \mathrm{m}$ thick F8BT layer, which is particularly relevant for potential roll-to-roll fabrication. These results clearly demonstrate the potential that this organic-inorganic composite EIL material has for the realisation of cheap, scalable and highly efficient, printable HyLED devices. 


\section{Introduction}

Polymer and other soluble semiconductor light emitting diodes (LEDs) have been the subject of intense research activity due to their compatibility with high throughput printing-based manufacturing for displays.[1] First commercial inkjet-printed devices have now reached the market but there is still scope for improvement in both device performance and stability. Polymer LEDs (PLEDs) generally comprise a small number of layers due to the constraints of layer-onlayer solution deposition. A critical factor in their performance then becomes the choice of appropriate charge injection layers. For example low workfunction metals such as calcium and barium have traditionally been used as electron injection layers (EILs)[2-6] but these are both oxygen and moisture sensitive, requiring expensive inert-atmosphere processing and encapsulation.[7] Metal complexes like $\mathrm{LiF}$ and $\mathrm{Cs}_{2} \mathrm{CO}_{3}$ have also be utilised and offer somewhat greater stability.[8]

Organic-inorganic hybrid light emitting diodes (HyLEDs) make use of one or more air stable metal oxide charge injection layers to help increase the operational device lifetime.[9] Typically, HyLEDs are fabricated in an inverted architecture with an n-type metal oxide EIL deposited on top of a semi-transparent indium tin oxide (ITO) layer as cathode,[10-13] followed by the emissive layer (EML) and a high workfunction hole injection layer (HIL) plus top anode contact. Titanium $\left(\mathrm{TiO}_{2}\right)$, zirconium $\left(\mathrm{ZrO}_{2}\right)$ and zinc $(\mathrm{ZnO})$ oxides have all been used as HyLED EILs, with both dense and nanoporous film microstructures.[10,11,14]

$\mathrm{ZnO}$ is the focus of the present paper and is studied as an EIL within poly(9,9-dioctylfluoreneco-benzothiadiazole (F8BT) EML devices. Its deep conduction band at $4.1 \mathrm{eV}$ below vacuum (c.f. F8BT lowest unoccupied molecular orbital (LUMO) at $-3.5 \mathrm{eV}$ ) introduces a significantly larger electron injection barrier than for $\mathrm{TiO}_{2}(-3.8 \mathrm{eV})$ and $\mathrm{ZrO}_{2}(-3.0 \mathrm{eV}),[10,11]$ correspondingly 
reducing device performance. To overcome this limitation, thin interfacial conjugated polyelectrolyte layers (CPEs) have previously been added to improve electron injection.[15-17] However such CPEs can have long, ionic-motion-related, electroluminescence (EL) turn-on times (of order seconds) that make them unsuitable for display applications.[18-20] Additionally, the high temperatures (up to $450{ }^{\circ} \mathrm{C}$ ) used in the fabrication of $\mathrm{ZnO}$ (and other oxides)[10,11] are incompatible with flexible plastic substrates.[21] As an alternative approach, solutions of colloidal $\mathrm{ZnO}$ nanoparticles (NPs) fabricated at room temperature have been used to fabricate flexible devices. Issues remain, however, with particle agglomeration, leading to poor surface coverage on ITO and a consequence need for multiple deposition steps to achieve good performance.[22,23] Therefore presently there is a need for solution processed electron injection materials that can be fabricated in one step without the need for high annealing temperatures for the realisation of printable HyLEDs. ZnO nanoparticle/polyelectrolyte composites have been demonstrated as electron injection layers in conventional PLED device structures[24,25], however their use in inverted device structures remains underexplored and are likely to require re-optimisation for peak performance.

In this paper, we elucidate in detail the performance of a $\mathrm{ZnO}: \mathrm{CPE}$ composite EIL within inverted green-light-emitting F8BT HyLEDs, comparing layers with different weight fractions of $\mathrm{CPE}$ and $\mathrm{ZnO} \mathrm{NPs}$ to compact $\mathrm{ZnO}(\mathrm{c}-\mathrm{ZnO}), \mathrm{ZnO} \mathrm{NP}$ only and c-ZnO/CPE bilayer EILs. The CPE, namely poly[(9,9-bis((8-(3-methyl-1-imidazolium)octyl)-2,7-fluorene)-alt-(9,9-bis(2-(2methoxyethoxy)ethyl)-fluorene)] dibromide $\left(\mathrm{F}_{\mathrm{imFO}}-\mathrm{Br}\right)$ is blended with conventional ZnO NPs, producing an EIL that can be solution processed as a single layer without the need for any additional annealing step and consequently that has great potential for flexible HyLEDs. Optimisation of both the CPE:ZnO NP EIL composition and the F8BT EML thickness enables 
excellent PLED performance with a maximum luminous efficiency of $16.5 \mathrm{~cd} / \mathrm{A}\left(\right.$ at $\left.19,590 \mathrm{~cd} / \mathrm{m}^{2}\right)$ and a maximum luminous power efficiency of $5.4 \mathrm{~lm} / \mathrm{W}$ (at $258 \mathrm{~cd} / \mathrm{m}^{2}$ ) for $1.1 \mu \mathrm{m}$ EML thickness devices. The CPE:ZnO blend EILs offer several further advantages, namely (i) no high temperature annealing required unlike dense $\mathrm{ZnO}$, (ii) fast EL turn-on times $(\approx 7 \mu$ s) compared to $\mathrm{ZnO} / \mathrm{CPE}$ bilayers and (iii) improved film quality in terms of better surface coverage and reduced roughness relative to $\mathrm{ZnO} \mathrm{NP}$ only layers. The latter leads to the requirement of only a single deposition step and taken together they offer great potential for the fabrication of cheap, scalable and highly efficient flexible HyLED devices.

\section{Results and Discussion}

To assess the suitability of CPE:ZnO NP composite materials in HyLEDs, EILs with different CPE weight fractions, specifically 0 ( $\mathrm{ZnO} \mathrm{NP}$ only), 2.25, 4.5, 9 and $18 \mathrm{wt} \%$, were prepared and deployed in ITO/EIL/F8BT/MoO$/ \mathrm{Au}$ PLED structures. The average size (diameter) of the bare $\mathrm{ZnO}$ NPs is $5.5 \mathrm{~nm}$, whilst the average feature size for CPE:ZnO NP composite films is 13.4 nm.[24] We also compared the best performing CPE:ZnO NP EIL devices to c-ZnO and c$\mathrm{ZnO} / \mathrm{CPE}$ bilayer EIL PLEDs (see below). Figure 1(a) shows the device configuration of the HyLEDs with CPE:ZnO NP EILs and Figure 1(b) shows the corresponding energy level diagram, whilst Figure 1(c) shows the CPE:ZnO NP composite chemical structure. 
(a)

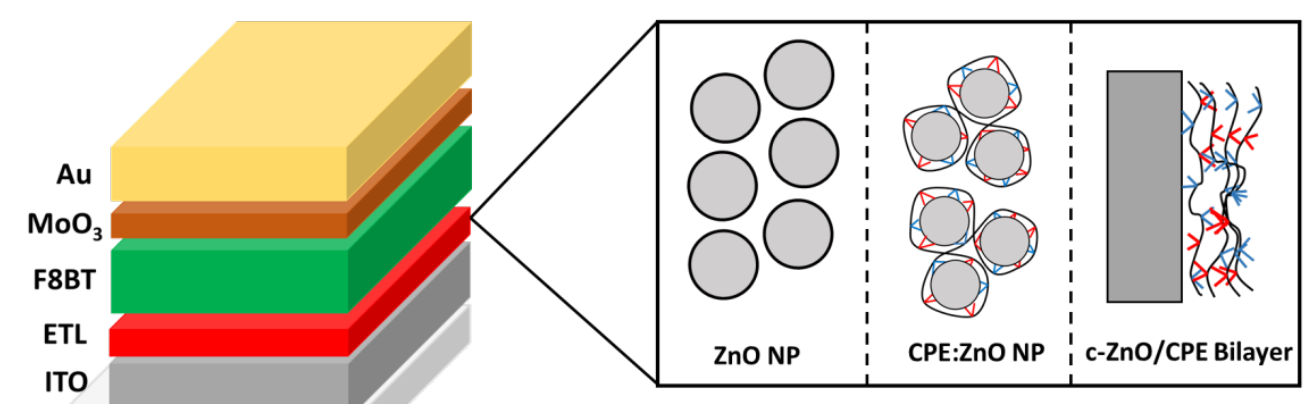

Substrate

(b)

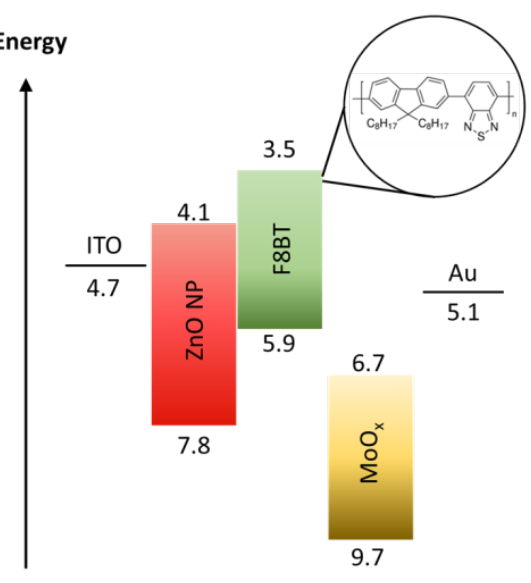

(c)

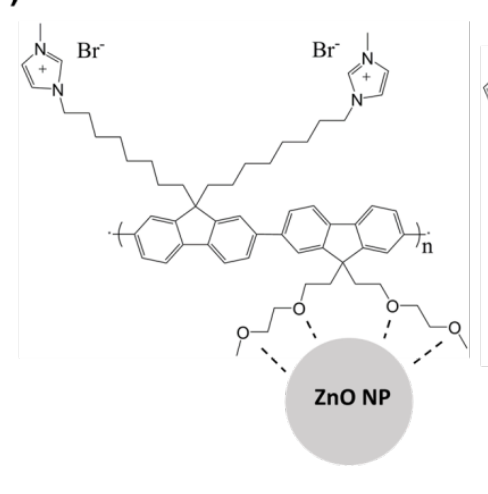

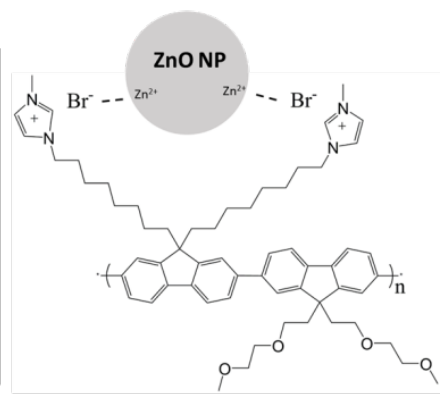

Figure 1: (a) Schematic diagram of an ITO/EIL $(35 \mathrm{~nm}) / \mathrm{FBBT}(75 \mathrm{~nm}) / \mathrm{MoO}_{s}(10 \mathrm{~nm}) / \mathrm{Au}(100$ nm) HyLED employing a CPE:ZnO NP composite EIL and (b) corresponding energy level diagram (in eV below vacuum). (c) Schematic chemical structure for CPE:ZnO NP composite with coordinate bonding between the $\mathrm{CPE}$ ethylene glycol side-chain oxygen atoms and $\mathrm{ZnO} \mathrm{NP}$ surface (left) and/or the $\mathrm{CPE} \mathrm{Br-} \mathrm{anions} \mathrm{and} \mathrm{NP} \mathrm{Zn}^{2+}$ ions (right). The expanded illustration of the EIL shows the structure of the CPE:ZnO NP composite, with the red and blue protuberances representing co-ordinate bonding between the $\mathrm{Zn}^{2+}$ ions and the oxygen moieties and $\mathrm{Br}$ ions respectively. 

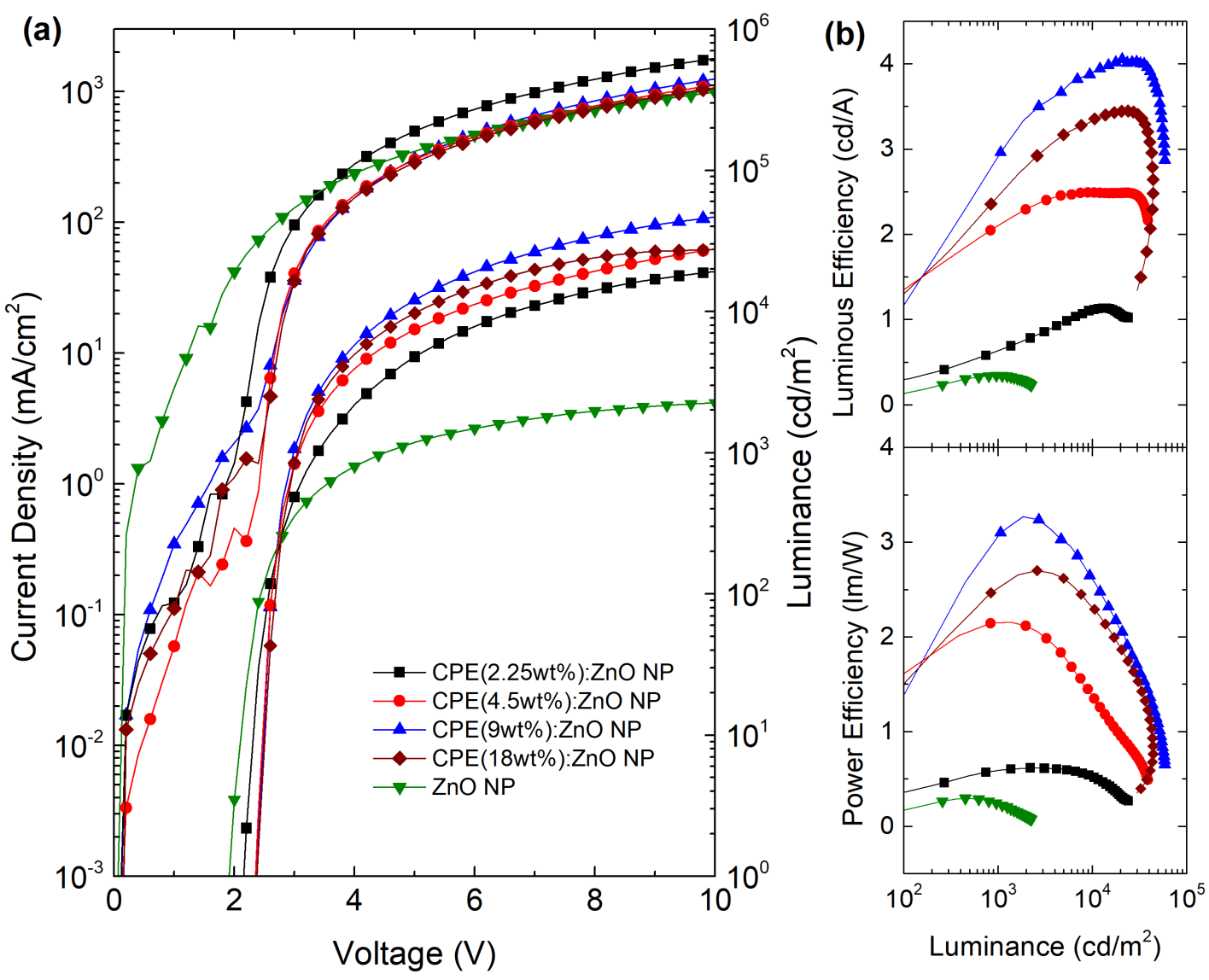

Figure 2: $\operatorname{CPE}(x$ wt $\%): Z n O ~ N P$ EIL HyLED device performance. (a) current density and luminance $v s$ voltage (J-V-L) and (b) luminous efficiency (cd/A) and luminous power efficiency $(\mathrm{lm} / \mathrm{W}) v s$ luminance for $x=0,2.25,4.5,9$ and $18 \mathrm{wt} \%$ composite EIL layers.

Figure 2(a) shows the direct current (DC) density-voltage-luminance (J-V-L) characteristics for $75 \mathrm{~nm}$ thickness F8BT EML HyLEDs with $x$ wt $\%$ CPE:ZnO NP composite EILs. The ZnO NP only $(x=0)$ device shows the lowest luminance turn-on voltage (as required to reach $1 \mathrm{~cd} / \mathrm{m}^{2}$ luminance), $\mathrm{V}_{\mathrm{on}}=2.0 \mathrm{~V}$. The low turn-on voltage could be associated with the rougher $\mathrm{ZnO} \mathrm{NP}$ surface causing preferred injection points; however in compact ZnO EIL film devices,[15,26] the low $\mathrm{V}_{\mathrm{on}}$ values for $\mathrm{ZnO}$ only devices have previously been proposed to be due to straightforward injection of holes through $\mathrm{MoO}_{3}$ into the $\mathrm{F} 8 \mathrm{BT}$ resulting in hole accumulation at the $\mathrm{F} 8 \mathrm{BT} / \mathrm{ZnO}$ interface. This in turn generates an internal electric field that assists injection of electrons. As the 
CPE wt $\%$ loading increases, the $\mathrm{V}_{\text {on }}$ values also slightly increase, to $2.2 \mathrm{~V}$ for $2.25 \mathrm{wt} \% \mathrm{CPE}$ and then to $2.4 \mathrm{~V}$ for $4.5,9$ and $18 \mathrm{wt} \% \mathrm{CPE}$. The latter value is much closer to the average F8BT EML photon emission energy; the EL spectrum (Figure S1) peaks at $541 \mathrm{~nm}$ and has FWHM linewidth of $80 \mathrm{~nm})$.

The $\mathrm{ZnO}$ NP only EIL HyLED shows an initial rapid increase in luminance above $\mathrm{V}_{\text {on }}$, up to 2.5 $\mathrm{V}$, however both the DC current density and luminance then saturate more quickly than for the CPE:ZnO NP composite EIL devices, eventually reaching a luminance, $L=2,257 \mathrm{~cd} / \mathrm{m}^{2}$ at $10 \mathrm{~V}$. This results in relatively low maximum luminous efficiency $(L E)$ and luminous power efficiency $(P E)$ values $L E_{\max }=0.34 \mathrm{~cd} / \mathrm{A}\left(\right.$ at $\left.4.4 \mathrm{~V}, 962 \mathrm{~cd} / \mathrm{m}^{2}\right)$ and $P E_{\max }=0.301 \mathrm{~m} / \mathrm{W}\left(\right.$ at $\left.3.2 \mathrm{~V}, 451 \mathrm{~cd} / \mathrm{m}^{2}\right)$. By contrast, the $x \mathrm{wt} \% \mathrm{CPE}: \mathrm{ZnO}$ NP composite EIL devices show much larger increases in luminance above turn-on, reaching $L=19,260,27,780,46,760$ and 44,260 cd/m² at $10 \mathrm{~V} \mathrm{DC}$ for $x=2.25,4.5$, 9 and $18 \mathrm{wt} \%$, respectively. This translates into improved maximum device efficiencies of $L E_{\max }=$ $1.14,2.49,4.06$ and $3.45 \mathrm{~cd} / \mathrm{A}$ and $P E_{\max }=0.62,2.15,3.27$ and $2.70 \mathrm{~lm} / \mathrm{W}$ for $x=2.25,4.5,9$ and $18 \mathrm{wt} \%$, respectively. The ethylene glycol side-chains $\mathrm{F}_{\mathrm{imFO}}-\mathrm{Br}$ have been shown to passivate $\mathrm{ZnO}$ NP surface defects by forming coordinate bonds with $\mathrm{Zn}^{2+}$ ions, as well as passivation because of bonding between the bromide anions and zinc cations.[24] This also allows the formation of uniform CPE:ZnO NP blends.[24] Passivation reduces F8BT luminescence quenching by the $\mathrm{ZnO}$ NPs[24,25]; to demonstrate this transient photoluminescence decay curves of F8BT thin films deposited on top of different CPE:ZnO EILs were recorded via time-correlated single photon counting (TCSPC) spectroscopy and are shown in Figure S2. We find that exciton lifetime of F8BT is only $1.62 \mathrm{~ns}$ when deposited upon $\mathrm{ZnO} \mathrm{NP}$ only. However, this lifetime increases to 1.71 , $1.73,1.81$ and $1.88 \mathrm{~ns}$ for $2.25 \mathrm{wt} \%, 4.5 \mathrm{wt} \%, 9 \mathrm{wt} \%$ and $18 \mathrm{wt} \% \mathrm{CPE}$ blends respectively showing 
the passivating effect of the CPE on the $\mathrm{ZnO}$ NPs and reduction in F8BT luminescence quenching via increase in radiative lifetime of F8BT exciton.

Figure $\mathbf{S 3}$ shows J-V-L and efficiency data for a HyLED device comprising of only an ITO/CPE electron injection layer with no ZnO NPs present (i.e. a CPE only EIL layer). Here, the luminance turn-on is $2.4 \mathrm{~V}$ and a luminance of $\mathrm{L}=1,475 \mathrm{~cd} / \mathrm{m}^{2}$ is reached at $10 \mathrm{~V}$. However, the maximum luminance was found to be $\mathrm{L}_{\max }=4,011 \mathrm{~cd} / \mathrm{m}^{2}($ at $7.4 \mathrm{~V})$. The device efficiencies are reduced to only $\mathrm{LE}_{\max }=0.70 \mathrm{~cd} / \mathrm{A}\left(\right.$ at $\left.2,450 \mathrm{~cd} / \mathrm{m}^{2}\right)$ and $\mathrm{PE}_{\max }=0.45 \mathrm{~lm} / \mathrm{W}\left(\right.$ at $\left.788.6 \mathrm{~cd} / \mathrm{m}^{2}\right)$. This shows that the presence of $\mathrm{ZnO}$ NPs is critical to device performance; electron injection into the F8BT likely occurs from the $\mathrm{ZnO} \mathrm{CB}$ whilst the $\mathrm{CPE}$ induces a vacuum level shift in the $\mathrm{ZnO}$ to aid this injection.

To test the universality of the $\mathrm{CPE}(9 \mathrm{wt} \%): \mathrm{ZnO}$ electron injection layer, F8BT PLED devices were fabricated in a conventional structure consisting of ITO/PEDOT:PSS/Poly(9,9dioctylfluorene-alt-N-(4-sec-butylphenyl)-diphenylamine) (TFB)/F8BT/EIL/Al. Here, we compared our best performing $\mathrm{CPE}(9 \mathrm{wt} \%): \mathrm{ZnO}$ EIL with $\mathrm{Ca}$, a commonly used low workfunction EIL. Figure S4 shows the J-V-L and efficiency data for each device; both show a luminance turnon of $\sim 2.0 \mathrm{~V}$, whilst the luminance at $10 \mathrm{~V}$ is $\mathrm{L}=62,790 \mathrm{~cd} / \mathrm{m}^{2}$ for $\mathrm{Ca}$ and $\mathrm{L}=95,490 \mathrm{~cd} / \mathrm{m}^{2}$ for $\mathrm{CPE}(9 \mathrm{wt} \%): \mathrm{ZnO} \mathrm{NP}$ devices. The device efficiencies for the $\mathrm{Ca}$ device is $\mathrm{LE}_{\max }=7.71 \mathrm{~cd} / \mathrm{A}$ (at $\left.4,489 \mathrm{~cd} / \mathrm{m}^{2}\right)$ and $\mathrm{PE}_{\max }=6.71 \mathrm{~lm} / \mathrm{W}\left(\right.$ at $\left.490 \mathrm{~cd} / \mathrm{m}^{2}\right)$ whilst the device efficiencies for the $\mathrm{CPE}(9 \mathrm{wt} \%): \mathrm{ZnO}$ device were $\mathrm{LE}_{\max }=10.8 \mathrm{~cd} / \mathrm{mA}\left(\right.$ at $\left.13,640 \mathrm{~cd} / \mathrm{m}^{2}\right)$ and $\mathrm{PE}_{\max }=9.31 \mathrm{~lm} / \mathrm{W}($ at 1,410 $\left.\mathrm{cd} / \mathrm{m}^{2}\right)$. This shows that highly efficient conventional-structure PLED devices can be fabricated using the $\mathrm{CPE}(9 \mathrm{wt} \%): \mathrm{ZnO}$ EIL with superior performance to a standard $\mathrm{Ca}$ EIL device. This is likely due to the reduction in interfacial quenching when using CPE:ZnO composite material compared to using a metal. 
(a)

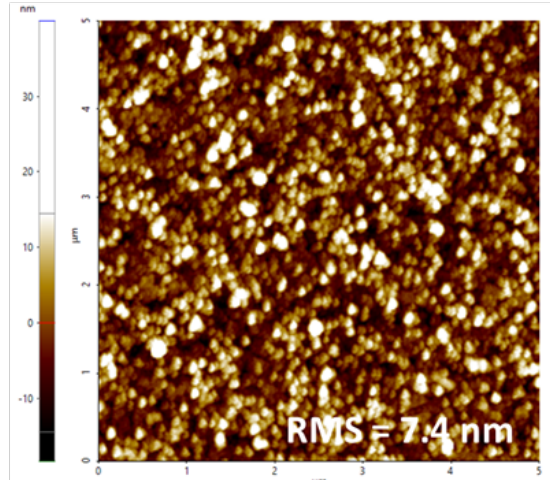

(c)

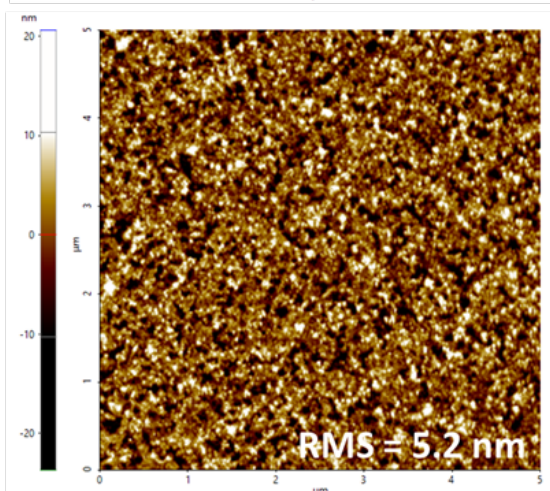

(b)

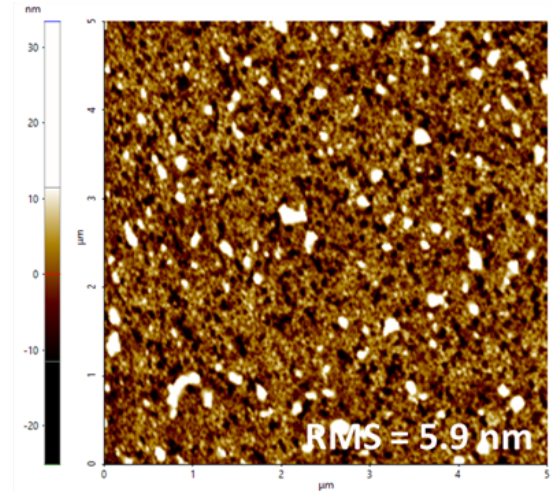

(d)

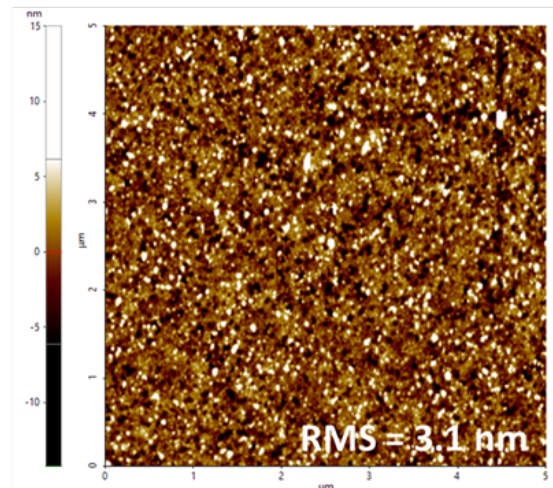

Figure 3: Atomic force microscope topology images ( $5 \mu \mathrm{m} \times 5 \mu \mathrm{m})$ of EIL films deposited on ITO coated glass substrates, comprising (a) ZnO NPs alone, (b) $\mathrm{CPE}(2.25 \mathrm{wt} \%)$ : $\mathrm{ZnO}$ NP composite, (c) $\mathrm{CPE}(4.5 \mathrm{wt} \%): \mathrm{ZnO} \mathrm{NP}$ composite and (d) $\mathrm{CPE}(9 \mathrm{wt} \%): \mathrm{ZnO} \mathrm{NP}$ composite.

The origin of the improvement in HyLED device efficiency is expected to be twofold. First, the $\mathrm{CPE}$ acts as a stabiliser for the $\mathrm{ZnO}$ NPs in solution, preventing aggregation.[24] To test this, the surface morphologies of the layers were investigated by atomic force microscopy (AFM). Figure 3 shows the 2D surface morphologies of EILs comprising ZnO NPs alone and CPE:ZnO NP composites with CPE fractions of 2.25, 4.5 and 9wt\%. The ZnO NP layer exhibited a high surface roughness with a root mean square (rms) value of $7.4 \mathrm{~nm}$. The addition of $2.25 \mathrm{wt} \% \mathrm{CPE}$ helped to reduce the rms roughness to $5.9 \mathrm{~nm}$, whilst 4.5 and $9 \mathrm{wt} \% \mathrm{CPE}$ fractions gave further reductions to 5.2 and $3.1 \mathrm{~nm}$, respectively. The $9 \mathrm{wt} \% \mathrm{CPE}: \mathrm{ZnO}$ NP EIL has a smooth, dense morphology 
with good coverage, facilitating homogeneous electron injection and hole blocking, both of which are desirable for device performance.[25,27]

Secondly, the inclusion of the CPE in composite EILs leads to a desirable shift in workfunction. Kelvin Probe measurements on ZnO NP only and $\mathrm{CPE}(x \mathrm{wt} \%): \mathrm{ZnO}$ NP composite films deposited on ITO (Figure 4) show that the workfunction, $\Phi$, of the EIL decreases as the CPE fraction increases. For the ZnO NP only EIL $\Phi=4.73 \mathrm{eV}$ whilst for composite EILs with 2.25, 4.5, 9 and $18 \mathrm{wt} \% \mathrm{CPE}$ the $\Phi$ values are respectively $4.63,4.37,4.22$ and $4.20 \mathrm{eV}$, a reduction in workfunction of up to $0.53 \mathrm{eV}$. The shift in workfunction can be attributed to the formation of interfacial dipoles between the $\mathrm{CPE}$ and $\mathrm{ZnO} \mathrm{NPs}$ due to bonding between the $\mathrm{F} \mathrm{imFO}_{4}-\mathrm{Br}$ bromide ions and/or ethylene glycol side-chain oxygen atoms and $\mathrm{Zn}^{2+}$ ions.[24] This can be represented by a down shift, $\Delta$, in vacuum level as indicated in Figure 4,[28,29] where the electron injection energy barrier, $\phi_{\mathrm{b}}$, between the EIL and F8BT EML also then decreases. It is also evident from Figure 2 that devices with composite EILs show lower DC current densities below EL turnon, suggestive of better hole blocking when the $\mathrm{CPE}$ is present. Increasing the fraction of CPE from $9 \%$ to $18 \%$ appears to yield only a negligible increase in vacuum level shift, implying that electron injection is not significantly enhanced and additional quenching is likely the reason for the decrease in performance from $\mathrm{CPE}(9 \mathrm{wt} \%): \mathrm{ZnO}$ to $\mathrm{CPE}(18 \mathrm{wt} \%): \mathrm{ZnO}$ devices. 

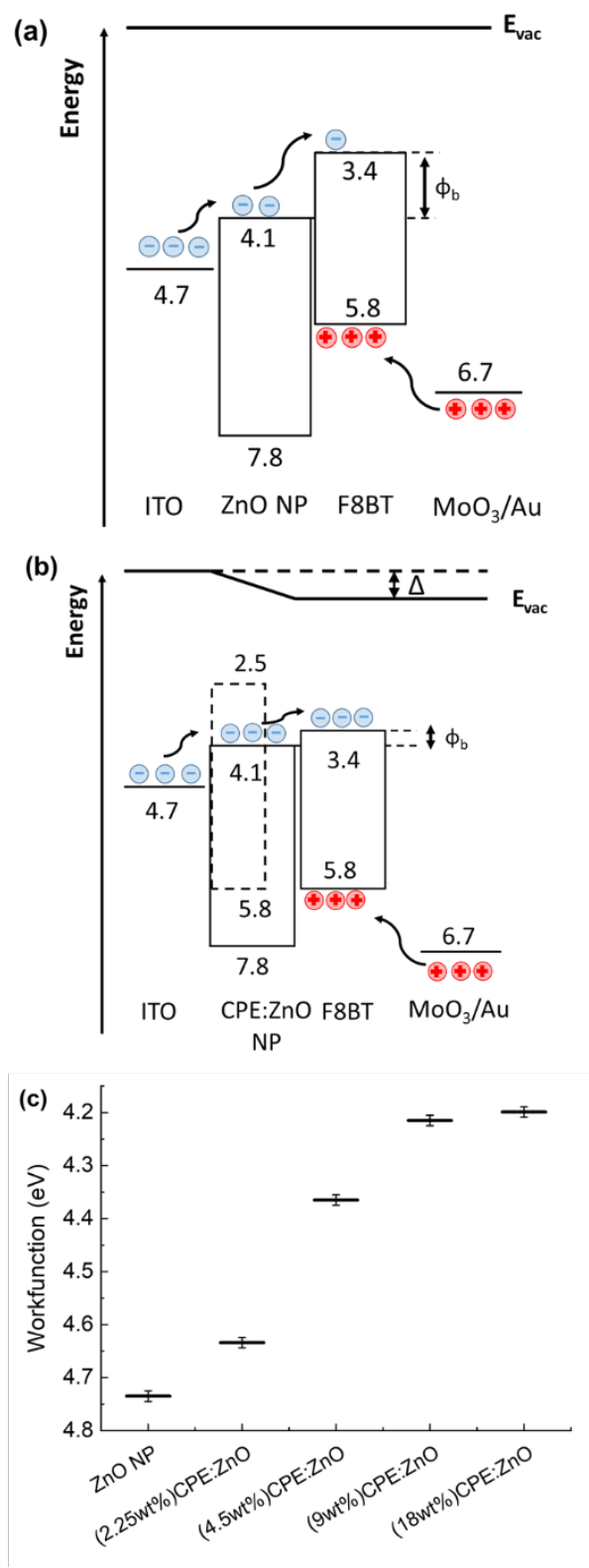

Figure 4: Schematic energy level diagram for charge injection processes in HyLEDs with (a) $\mathrm{ZnO}$ NP only and (b) composite CPE:ZnO NP EILs on ITO. The CPE component induces a vacuum level shift $(\Delta)$ that reduces the electron injection barrier $\left(\phi_{\mathrm{b}}\right)$. The measured workfunction values for $\mathrm{ZnO} \mathrm{NP}$ only and 2.25, 4.5, 9 and $18 \mathrm{wt} \% \mathrm{CPE}$ fraction composites are compared in (c).

One key advantage of inducing a workfunction shift in this manner is that the mobile ions present in the CPE (the bromide ions) are now fixed due to the coordination bonding with $\mathrm{ZnO}$ NP. Early 
HyLEDs containing CPE layers used a bilayer of compact zinc oxide (c-ZnO) and CPE deposited on top to aid electron injection via modification of the workfunction of the $\mathrm{ZnO}$ layer due to the formation of dipoles at the $\mathrm{ZnO} / \mathrm{CPE}$ interface.[15,16,30] As mentioned, c-ZnO/CPE bilayers are undesirable in HyLEDs due to high processing temperatures required for $\mathrm{ZnO}$ layer (making it unsuitable for flexible substrates) and long EL and current turn-on times. To test the performance of $9 \mathrm{wt} \% \mathrm{CPE}: \mathrm{ZnO} \mathrm{NP}$ composite EIL against conventional $\mathrm{ZnO} / \mathrm{CPE}$ devices, c-ZnO and c$\mathrm{ZnO} / \mathrm{CPE}$ bilayer EIL F8BT HyLEDs were fabricated and compared. Figure 5 compares the J-V$\mathrm{L}$ and efficiency characteristics of devices containing c-ZnO, c-ZnO/CPE bilayer and CPE (9 $\mathrm{wt} \%): \mathrm{ZnO} \mathrm{NP}$ composite layer as the EIL.

In similar fashion to $\mathrm{ZnO} \mathrm{NP}$ only EIL devices, c- $\mathrm{ZnO}$ devices show a low $\mathrm{V}_{\mathrm{on}}=2.0 \mathrm{~V}$ but reach a slightly higher luminance at $10 \mathrm{~V}$, namely $\mathrm{L}=6,453 \mathrm{~cd} / \mathrm{m}^{2}$, with $\mathrm{LE}_{\max }=0.52 \mathrm{~cd} / \mathrm{A}$ (at 4,775 $\left.\mathrm{cd} / \mathrm{m}^{2}\right)$ and $\mathrm{PE}_{\max }=0.32 \mathrm{~lm} / \mathrm{W}\left(\right.$ at $\left.1,097 \mathrm{~cd} / \mathrm{m}^{2}\right)$. Spin-coating $\mathrm{F} \mathrm{imFO}{ }_{4} \mathrm{CPE}$ on top of the $\mathrm{c}-\mathrm{ZnO}$ layer increases the HyLED luminance up to $36,900 \mathrm{~cd} / \mathrm{m}^{2}$ at $10 \mathrm{~V}$ through bromide-Zn and oxygen$\mathrm{Zn}$ bonding allowing passivation of the $\mathrm{ZnO}$ surface, reducing $\mathrm{ZnO}$ defect $\mathrm{EL}$ quenching. $[24,31,32]$ These devices then achieve $\mathrm{LE}_{\max }=3.8 \mathrm{~cd} / \mathrm{A}\left(\right.$ at $\left.21,859 \mathrm{~cd} / \mathrm{m}^{2}\right)$ and $\mathrm{PE}_{\max }=3.0$ $\mathrm{lm} / \mathrm{W}$ (at 2,593 cd/m²), only slightly lower than for the CPE (9 wt\%):ZnO NP EIL devices but with the added requirement of a high temperature processing step.

The EL spectra of the c- $\mathrm{ZnO}$ and $\mathrm{ZnO} / \mathrm{CPE}$ bilayer devices are shown in Figure S5. Here, we find that the spectra are slightly red shifted and broadened compared to the CPE:ZnO NP composite devices, peaking at $565 \mathrm{~nm}$ with a FWHM of 93 and $89 \mathrm{~nm}$ respectively. This difference could be due to scattering or weak microcavity effects caused by the difference in electron injection layers. 
Figures 5 (c) and (d) show the normalised transient response curves for current density (J) and EL intensity following application of $5 \mathrm{~V}$ amplitude, $1 \mathrm{~Hz}$ repetition rate, square wave voltage pulses. This allows the rise time, $\tau$, of the device to be determined by finding the intercept of the EL saturation and the tangent of the rising edge of the signal.$^{36}$ The current density responses of the c-ZnO alone and CPE:ZnO NP composite devices both closely follow the voltage input signal. The resulting EL signals turn-on just as fast but then show a slow signal drop $(\sim 3 \%)$ over the course of the $0.5 \mathrm{~s}$ pulse. Such behaviour is seen in many polymer LEDs and is often reversible, implicating the effect of charge trapping on internal fields.[33-35] Conversely, for the c$\mathrm{ZnO} / \mathrm{F} \mathrm{imFO}_{4}$ bilayer devices, both the $\mathrm{J}$ and EL signals show an initial rapid rise up to $\sim 75 \%$ of peak value, followed by a slower rise with time constant $\tau \sim 0.2 \mathrm{~s}$. Such a delayed response has previously been observed for other CPE EIL devices due to the rearrangement of mobile ions under the applied electric field.[18-20,36] It is notable, therefore, that the CPE (9 wt $\%): \mathrm{ZnO} \mathrm{NP}$ composite EIL HyLEDs do not show this effect but rather behave the same as c-ZnO EIL devices; their $\mathbf{J}$ and EL rise times are fast $(\tau \sim 7 \mu \mathrm{s})$. In comparison the bilayer EIL devices show much longer rise times $(\tau \sim 0.4 \mathrm{~s})$. The CPE:ZnO NP composite EIL materials thereby yield both (i) high EL efficiency and (ii) fast EL response without any high temperature processing step which makes them attractive for display applications. Another possible advantage of using a $\mathrm{CPE}: \mathrm{ZnO}$ composite could be improved operational lifetime; previous observations in the literature note longer operational lifetimes when using a polyelectrolyte: $\mathrm{ZnO}$ composite EIL as opposed to using only polyelectrolyte EILs.[37]

The otherwise mobile CPE bromide counterions are 'locked' in place by the NPs in the CPE (9 wt\%):ZnO NP composite EIL.[24] Thermal treatment under an applied bias has also been observed to allow these ions to become locked, resulting in similar reductions in EL rise time.[38] Other 
approaches to reducing EL rise time include tailoring the electronic structure of the CPE; for instance using an F8BT based CPE in an F8BT EML PLED can produce fast turn-on times on the order of $\sim 10 \mu \mathrm{s}$ by reducing the injection barrier between aluminium and the CPE which in turn prevents the build-up of a local field that acts upon the ions.[36] 

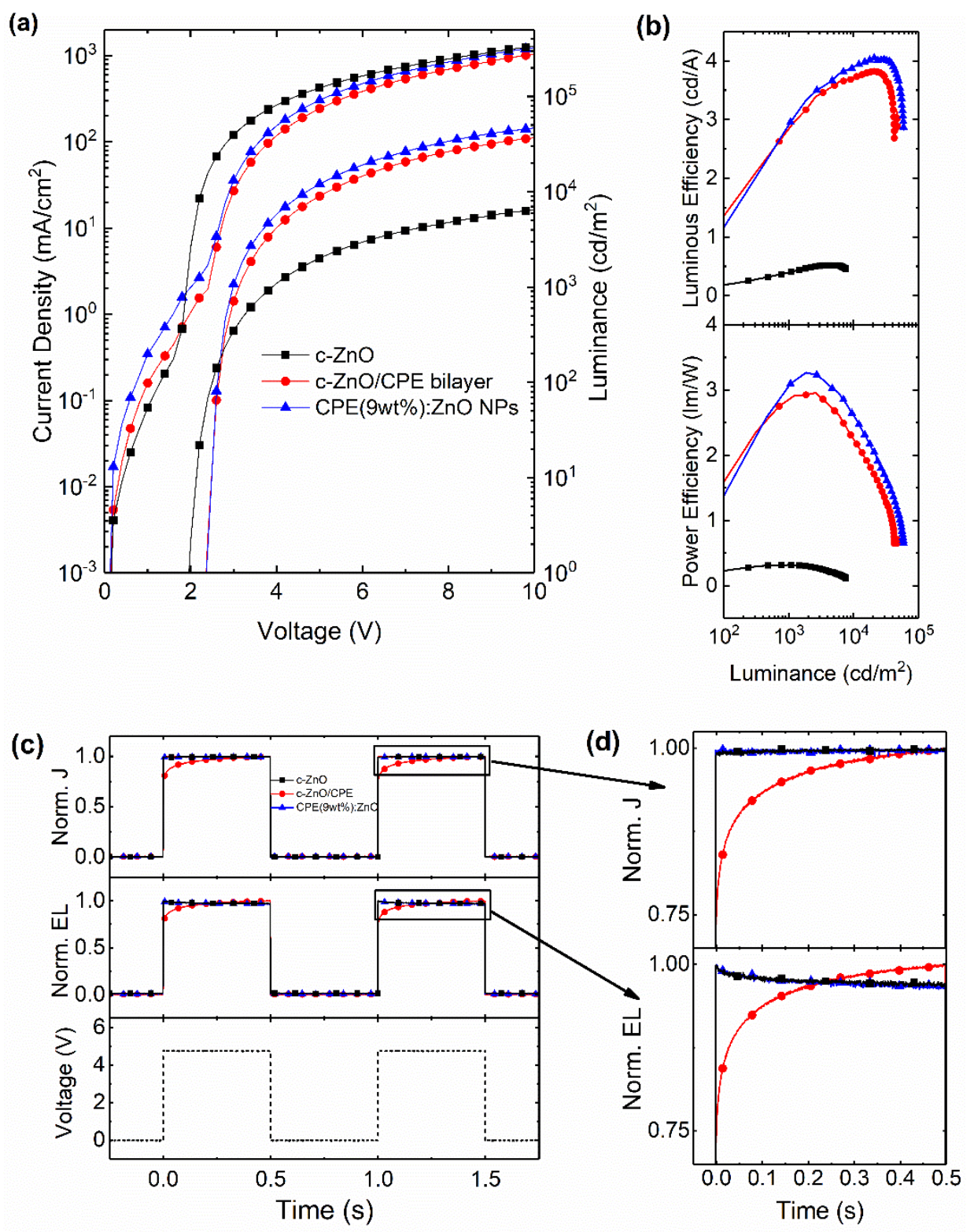

Figure 5: Device performance for F8BT HyLEDs with c-ZnO, c-ZnO/CPE bilayer and CPE (9 wt\%):ZnO NP composite EIL layers. (a) DC current density and steady state luminance versus voltage (J-V-L). (b) Luminous efficiency and luminous power efficiency versus luminance. (c) Normalised transient current density (J, upper panel) and electroluminescence (EL, middle panel). The corresponding $5 \mathrm{~V}$ amplitude, $1 \mathrm{~Hz}$ repetition rate, square wave voltage excitation pulses are also shown (lower panel). (d) Magnified portion of normalised current (upper panel) and EL (lower panel) transients. 
As a final characterisation we used the CPE ( $9 \mathrm{wt} \%)$ : $\mathrm{ZnO}$ composite EIL layer in thicker EML devices to test its potential for more readily scalable, high efficiency, printable LEDs.[39,40] The use of thick $(>1 \mu \mathrm{m})$ EMLs is especially important in roll-to-roll printing where robust, faulttolerant and reproducible films are required.[41] Figure 6 shows the J-V-L and LE and PE device efficiencies for $1.1 \mu \mathrm{m}$ thickness F8BT EML HyLEDs, with the increase in $\mathrm{V}_{\text {on }}$ to $5.0 \mathrm{~V}$ (from 2.4 V for $75 \mathrm{~nm}$ thickness F8BT EML devices) consistent with electric-field dependent charge injection.[42] These devices achieve a notably higher maximum luminance, reaching $L_{\max }=77,130$ $\mathrm{cd} / \mathrm{m}^{2}$ at $25 \mathrm{~V}$ (c.f. $\mathrm{L}_{\max }=46,760 \mathrm{~cd} / \mathrm{m}^{2}$ at $10 \mathrm{~V}$ for $75 \mathrm{~nm}$ EML thickness). The maximum efficiencies obtained also increase significantly to $\mathrm{LE}_{\max }=16.5 \mathrm{~cd} / \mathrm{A}\left(\right.$ at $18.2 \mathrm{~V}, 19,590 \mathrm{~cd} / \mathrm{m}^{2}$ ) and $\mathrm{PE}_{\max }=5.4$ $1 \mathrm{~m} / \mathrm{W}\left(\right.$ at $\left.7.2 \mathrm{~V}, 258 \mathrm{~cd} / \mathrm{m}^{2}\right)$ from $\mathrm{LE}_{\max }=4.10 \mathrm{~cd} / \mathrm{A}\left(\right.$ at $\left.6.4 \mathrm{~V}, 22,240 \mathrm{~cd} / \mathrm{m}^{2}\right)$ and $\mathrm{PE}_{\max }=3.3 \mathrm{~lm} / \mathrm{W}$ (at $3.2 \mathrm{~V}, 1,844 \mathrm{~cd} / \mathrm{m}^{2}$ ) for the thinner EML devices. The LE of the $1.1 \mu \mathrm{m}$ thick devices remains high ( $>15 \mathrm{~cd} / \mathrm{A}$ ) up to a current density $\mathrm{J}=450 \mathrm{~mA} / \mathrm{cm}^{2}$ (at $21.8 \mathrm{~V}$ where $\left.\mathrm{L}=68,350 \mathrm{~cd} / \mathrm{m}^{2}\right)$ but there is then a notable roll-off in efficiency, decreasing to $8.6 \mathrm{~cd} / \mathrm{A}$ at $\mathrm{J}=790 \mathrm{~mA} / \mathrm{cm}^{2}$ (for $25 \mathrm{~V}$ where $\left.\mathrm{L}=67,630 \mathrm{~cd} / \mathrm{m}^{2}\right)$. The significant increase in device efficiency is attributed to the introduction of a broad recombination zone within the thick F8BT EML layer, as already noted for conventional (non-composite EIL) thick HyLEDs.[42,43] This reduces the fraction of excitons formed near one or other electrode, reducing interfacial quenching and thus improving device efficiency. Figure S6 also shows the normalised EL emission of the $1.1 \mu \mathrm{m}$ F8BT device. Here, the emission is slightly red-shifted and broadened compared to the $75 \mathrm{~nm}$ F8BT EML devices, peaking at $547 \mathrm{~nm}$ with a FWHM of $83 \mathrm{~nm}$. This is likely due to a change in the weak microcavity effect from the large change in EML thickness. The turn-on, luminance, efficiency and CIE $(x, y)$ data for each of the HyLED structures studied in this paper is summarised in Table 1. 

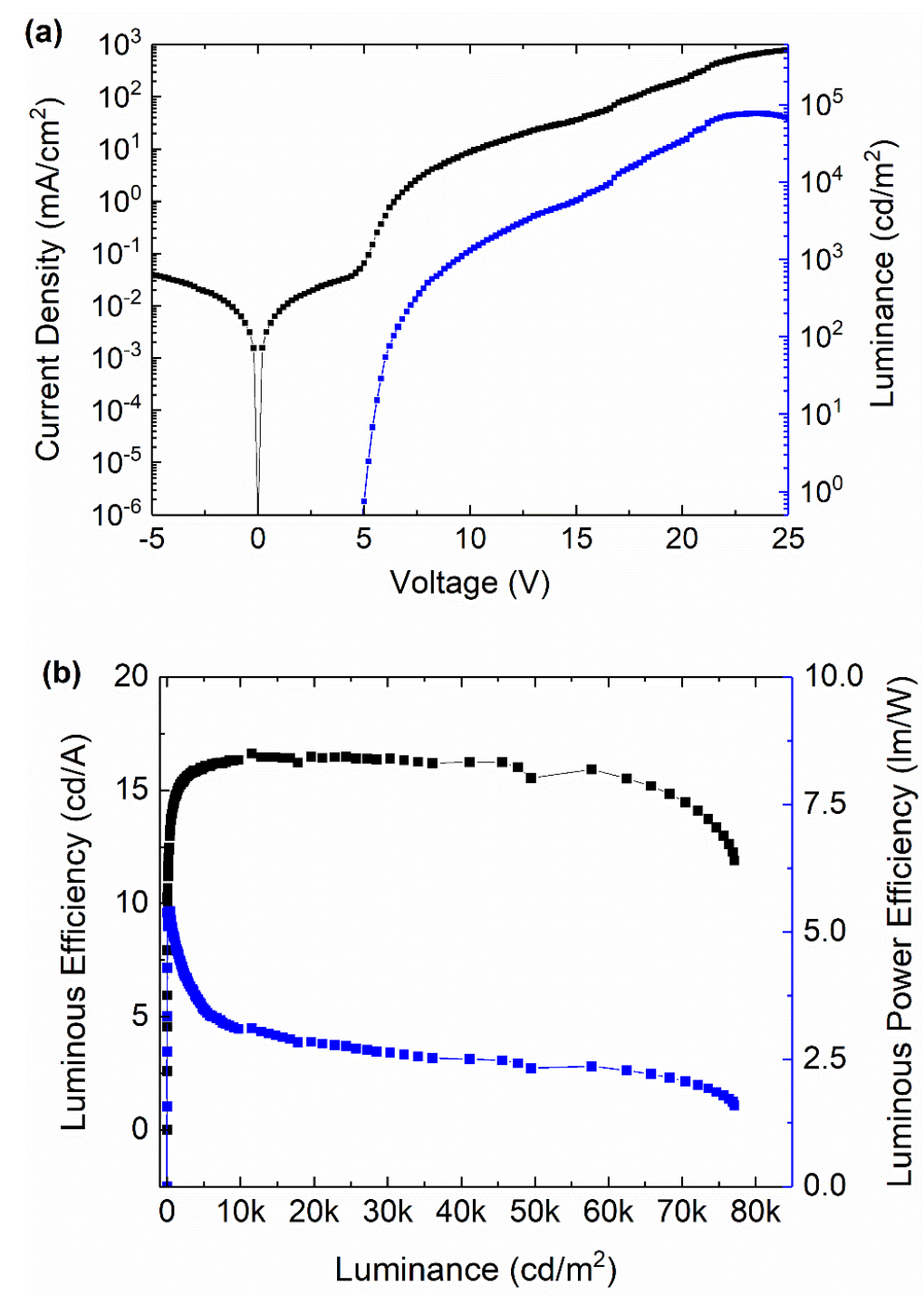

Figure 6: Device performance for $1.1 \mu \mathrm{m}$ F8BT EML HyLEDs with CPE (9 wt\%):ZnO NP composite EIL layers. (a) Current density and luminance versus voltage (J-V-L) and (b) Luminous efficiency and luminous power efficiency versus luminace

Table 1: Summary of F8BT EML HyLED devices fabricated with ZnO NP, $(x$ wt $\%)$ CPE:ZnO NP composite, c- $\mathrm{ZnO}$ and c-ZnO/CPE bilayer EILs. Unless otherwise stated the F8BT EML thickness was $75 \mathrm{~nm}$.

- Luminance taken at $23.4 \mathrm{~V}$ 


\begin{tabular}{|c|c|c|c|c|c|c|}
\hline EIL & $\begin{array}{c}\text { Turn-on } \\
(\mathrm{V})\end{array}$ & $\begin{array}{c}\text { Luminance } \\
@ 10 \text { V } \\
\left(\mathbf{c d} / \mathbf{m}^{2}\right)\end{array}$ & $\begin{array}{l}\mathbf{L E}_{\max }(\mathbf{c d} / \mathbf{A}) \\
(@ \text { bias, } \\
\text { luminance })\end{array}$ & $\begin{array}{c}\mathbf{P E}_{\max }(\mathbf{I m} / \mathbf{W}) \\
\text { (@ bias, } \\
\text { luminance) }\end{array}$ & $\begin{array}{c}\text { Max. EQE } \\
(\%)(@ \\
\text { bias, } \\
\text { luminance) }\end{array}$ & $\begin{array}{l}\text { CIE } \\
(x, y)\end{array}$ \\
\hline $\mathrm{ZnO}$ NP & 2.0 & 2,257 & $\begin{array}{c}0.34 \text { (@ } 4.4 \\
\left.\mathrm{~V}, 962 \mathrm{~cd} / \mathrm{m}^{2}\right)\end{array}$ & $\begin{array}{c}0.30(@ 3.2 \\
\left.\mathrm{V}, 450 \mathrm{~cd} / \mathrm{m}^{2}\right)\end{array}$ & $\begin{array}{c}0.103 \text { @ @ } 4.4 \\
\text { V, } 962 \\
\left.\mathrm{~cd} / \mathrm{m}^{2}\right)\end{array}$ & $\begin{array}{l}(0.43, \\
0.56)\end{array}$ \\
\hline $\begin{array}{c}\mathrm{CPE}(2.25 \%): \mathrm{ZnO} \\
\text { composite }\end{array}$ & 2.2 & 19,260 & $\begin{array}{c}1.14(@ 7.8 \\
\mathrm{V}, 13,570 \\
\left.\mathrm{~cd} / \mathrm{m}^{2}\right)\end{array}$ & $\begin{array}{c}0.62(@ 4.0 \\
\mathrm{V}, 2,192 \\
\left.\mathrm{~cd} / \mathrm{m}^{2}\right)\end{array}$ & $\begin{array}{c}0.342(@ 7.8 \\
\mathrm{V}, 13,570 \\
\left.\mathrm{~cd} / \mathrm{m}^{2}\right)\end{array}$ & $\begin{array}{l}(0.43, \\
0.56)\end{array}$ \\
\hline $\begin{array}{l}\mathrm{CPE}(4.5 \%): \mathrm{ZnO} \\
\text { composite }\end{array}$ & 2.4 & 27,780 & $\begin{array}{c}2.49(@ 5.4 \\
\mathrm{V}, 8,976 \\
\left.\mathrm{~cd} / \mathrm{m}^{2}\right)\end{array}$ & $\begin{array}{c}2.15(@ 3.2 \\
\mathrm{V}, 1,373 \\
\left.\mathrm{~cd} / \mathrm{m}^{2}\right)\end{array}$ & $\begin{array}{c}0.743 \text { @ @ } 5.4 \\
\mathrm{~V}, 8,976 \\
\left.\mathrm{~cd} / \mathrm{m}^{2}\right)\end{array}$ & $\begin{array}{l}(0.43, \\
0.56)\end{array}$ \\
\hline $\begin{array}{l}\mathrm{CPE}(9 \%): \mathrm{ZnO} \\
\text { composite }\end{array}$ & 2.4 & 46,760 & $\begin{array}{c}4.10(@ 6.4 \\
\mathrm{V}, 22,240 \\
\left.\mathrm{~cd} / \mathrm{m}^{2}\right)\end{array}$ & $\begin{array}{c}3.27 \text { @ } 3.2 \\
\mathrm{~V}, 1,844 \\
\left.\mathrm{~cd} / \mathrm{m}^{2}\right)\end{array}$ & $\begin{array}{c}1.194(@ 6.4 \\
\mathrm{V}, 22,240 \\
\left.\mathrm{~cd} / \mathrm{m}^{2}\right)\end{array}$ & $\begin{array}{l}(0.43, \\
0.56)\end{array}$ \\
\hline $\begin{array}{l}\mathrm{CPE}(18 \%): \mathrm{ZnO} \\
\text { composite }\end{array}$ & 2.4 & 44,260 & $\begin{array}{c}3.45(@ 6.0 \\
\mathrm{V}, 22,200 \\
\left.\mathrm{~cd} / \mathrm{m}^{2}\right)\end{array}$ & $\begin{array}{c}2.70(@ 3.4 \\
\mathrm{V}, 2,603 \\
\left.\mathrm{~cd} / \mathrm{m}^{2}\right)\end{array}$ & $\begin{array}{c}0.985(@ 6.0 \\
\mathrm{V}, 22,200 \\
\left.\mathrm{~cd} / \mathrm{m}^{2}\right)\end{array}$ & $\begin{array}{l}(0.43, \\
0.56)\end{array}$ \\
\hline $\mathrm{c}-\mathrm{ZnO}$ & 2.0 & 6,453 & $\begin{array}{c}0.52(@ 7.4 \\
\mathrm{V}, 4,259 \\
\left.\mathrm{~cd} / \mathrm{m}^{2}\right)\end{array}$ & $\begin{array}{l}0.32(@ 4.0 \\
\mathrm{V}, 1,097 \\
\left.\mathrm{~cd} / \mathrm{m}^{2}\right)\end{array}$ & $\begin{array}{c}0.156 \text { (@ } 7.4 \\
\mathrm{~V}, 4,259 \\
\left.\mathrm{~cd} / \mathrm{m}^{2}\right)\end{array}$ & $\begin{array}{l}(0.46, \\
0.53)\end{array}$ \\
\hline $\begin{array}{c}\text { c- } \mathrm{ZnO} / \mathrm{CPE} \\
\text { bilayer }\end{array}$ & 2.4 & 36,900 & $\begin{array}{c}3.82(@ 7.0 \\
\mathrm{V}, 20,650 \\
\left.\mathrm{~cd} / \mathrm{m}^{2}\right)\end{array}$ & $\begin{array}{c}2.96(@ 3.6 \\
\mathrm{V}, 2,593 \\
\left.\mathrm{~cd} / \mathrm{m}^{2}\right)\end{array}$ & $\begin{array}{c}1.17(@ 7.0 \\
\mathrm{V}, 20,650 \\
\left.\mathrm{~cd} / \mathrm{m}^{2}\right)\end{array}$ & $\begin{array}{l}(0.46, \\
0.53)\end{array}$ \\
\hline $\begin{array}{c}\mathrm{CPE}(9 \%): \mathrm{ZnO} \\
\text { composite/1.1 } \mu \mathrm{m} \\
\text { F8BT }\end{array}$ & 5.0 & $77,130^{a}$ & $\begin{array}{c}16.5(@ 18.2 \\
\mathrm{V}, 19,590 \\
\left.\mathrm{~cd} / \mathrm{m}^{2}\right)\end{array}$ & $\begin{array}{c}5.4(@ 7.2 \mathrm{~V}, \\
\left.258 \mathrm{~cd} / \mathrm{m}^{2}\right)\end{array}$ & $\begin{array}{c}4.81(@ 18.2 \\
\mathrm{V}, 19,590 \\
\left.\mathrm{~cd} / \mathrm{m}^{2}\right)\end{array}$ & $\begin{array}{l}(0.44, \\
0.55)\end{array}$ \\
\hline
\end{tabular}

\section{Conlcusion}

In summary, we have demonstrated for the first time use of CPE:ZnO NP composites with varying $\mathrm{CPE}$ fraction as effective EILs in inverted F8BT EML HyLEDs. We observe an improvement in EIL film morphology with increasing CPE content, together with an increase in vacuum level shift that supports enhanced electron injection. The 9 wt\% CPE:ZnO EIL devices, 
in particular, show significantly improved device characteristics compared to c- $\mathrm{ZnO} / \mathrm{CPE}$ bilayer EIL HyLEDs, with both higher device efficiencies and substantially faster turn-on times, compatible with display application. Increasing the F8BT EML thickness from $75 \mathrm{~nm}$ to $1.1 \mu \mathrm{m}$ then allows demonstration of state-of-the-art efficiencies, $\mathrm{LE}_{\max }=16.5 \mathrm{~cd} / \mathrm{A}$ and $\mathrm{PE}_{\max }=5.4 \mathrm{~lm} / \mathrm{W}$, with $\mathrm{L}_{\max }=77,130 \mathrm{~cd} / \mathrm{m}^{2}$. The use of such a thick EML layer is particularly relevant to roll-to-roll device fabrication, where thick layers are required for fault-tolerance. This is also the first demonstration that blending CPEs with ZnO NPs causes the ions to 'lock' and thus produces fast electron injection, leading to luminance turn-on times on the $10^{-6} \mathrm{~s}$ timescale. By contrast, traditional $\mathrm{ZnO} / \mathrm{CPE}$ bilayer devices showed luminance turn-on times on the $10^{-1}$ timescale and therefore unsuitable for display applications.

Importantly, these results demonstrate that superior performance for single EML fluorescent PLEDs can be achieved using a simplified device architecture and facile fabrication processes. The CPE:ZnO NP composite EIL films can be formed in a one-step solution deposition process under ambient conditions with no annealing step, making them desirable for use in the highthroughput manufacture of printable LEDs. This approach could further be extended to different F8BT-based polymer EML structures[44] and to flexible optoelectronic devices more generally, including organic photovoltaic cells where the composite would operate as an electron extraction layer.

\section{Experimental}

\section{PLED Fabrication:}

Patterned ITO anode structures on glass substrates (size $12 \mathrm{~mm}$ x $8 \mathrm{~mm}$ ) were cleaned for 15 minutes each in a sequence of ultrasonic baths using acetone, isopropanol and detergent (Hellmanex III, $2 \%$ by volume in DI water), followed by oxygen plasma ashing in an Emitech 
K1050X plasma cleaner. Compact, $30 \mathrm{~nm}$ thickness, ZnO EILs were spin-coated (2000 rpm, 60 s) on top of the ITO from $0.3 \mathrm{M}$ sol-gel solutions of zinc acetate dihydrate and 2-aminoethanol dissolved in 2-methoxyethanol and annealed at $450{ }^{\circ} \mathrm{C}$ for 1 hour. For $\mathrm{ZnO} / \mathrm{CPE}$ bilayer EILs, a $\sim 10 \mathrm{~nm}$ thickness $\mathrm{F} \mathrm{imFO}_{4} \mathrm{CPE}$ (synthesised according to previous reports)[24] film was then spin-coated (3000 rpm, $60 \mathrm{~s}$ ) on top from a $3 \mathrm{mg} / \mathrm{ml}$ 2-methoxyethanol solution.

Colloidal zinc oxide nanoparticles were prepared according to previous reports and dispersed in 2-methoxyethanol at a concentration of $40 \mathrm{mg} / \mathrm{ml}$ with average particle size $=5.5 \mathrm{~nm}$.[24] $\mathrm{F}_{8} \mathrm{imFO}_{4}$ dissolved in 2-methoxyethanol at different concentrations was then added to a portion of this $\mathrm{ZnO}$ NP stock solution and the resulting mixture stirred to obtain a CPE:ZnO NP composite solution. Previous reports have shown that $\mathrm{ZnO}$ NPs disperse well when blended with $\mathrm{F} \mathrm{imFO}_{4}$, with the resulting average cluster size $=13.4 \mathrm{~nm}$. This is believed due to the CPE's ethylene oxide side chains being able to form coordinate bonds with zinc cations on the nanoparticle surface as well as bonds formed between the bromide and zinc cations.[24] ZnO NP and CPE:ZnO NP composite EILs of $\sim 30 \mathrm{~nm}$ thickness were spin coated (1000 rpm, $30 \mathrm{~s}$ ) onto pre-cleaned ITO-coated glass substrates.

F8BT EMLs of two thicknesses were next deposited on top of the different EIL layers; $75 \mathrm{~nm}$ films were spin coated (2000 rpm, $60 \mathrm{~s})$ from $10 \mathrm{mg} / \mathrm{ml}$ and $1.1 \mu \mathrm{m}$ films (1500 rpm, $60 \mathrm{~s}$ ) from $40 \mathrm{mg} / \mathrm{ml}$ toluene solutions. To complete the PLEDs an MBraun thermal evaporator was used to deposit a top molybdenum oxide $(10 \mathrm{~nm})$ hole injection layer (HIL) and a gold $(100 \mathrm{~nm})$ anode.

\section{PLED characterisation:}

PLEDs were characterised at room temperature in a sealed sample chamber under nitrogen, using a computer-controlled Keithley Source Measure unit to apply a bias voltage to the chosen 
pixel (each substrate comprised 6 PLED pixels) and to measure the resultant current. A Minolta LS100 spot luminance meter measured the corresponding pixel luminance and electroluminescence spectra were recorded using an Ocean Optics USB 2000 CCD spectrometer equipped with a fiber light collection bundle. The PLED EL intensity and current density transient responses were probed using a HP 3325B pulse generator and monitored with a digital oscilloscope (Tektronix DPO 3054); a fast Si-photodiode was used to detect the EL signal.

EIL characterisation:

Atomic force microscopy (AFM) topographic images of the EILs were obtained using a Park NX10 AFM in non-contact mode. Kelvin probe measurements were performed using a KP Technology APS04 system. During the latter measurements the ITO substrate was connected to ground. The workfunction was determined from the contact potential difference measured by the vibrating top Kelvin probe ( $2 \mathrm{~mm}$, gold tip) and from the work function of the tip $(\approx 4.5-4.6 \mathrm{eV})$,

determined using a silver reference. TCSPC measurements of F8BT/EIL bilayers were taken using an Edinburgh Instruments FLS1000 spectrometer, with an excitation wavelength of $405 \mathrm{~nm}$ and detection wavelength of $550 \mathrm{~nm}$.

\section{Acknowledgement}

The authors thank Cambridge Display Technology Ltd for supplying the F8BT polymer. I.H. and J.S.K. also acknowledge funding via a UK Engineering and Physical Sciences Research Council (EPSRC) Plastic Electronics Doctoral Training Centre (EP/G037515/1) studentship. The authors further thank Matyas Daboczi for assistance with TCSPC measurements. 


\section{References}

[1] J.H. Burroughes, D.D.C. Bradley, A.R. Brown, R.N. Marks, K. Mackay, R.H. Friend, P.L. Burns, A.B. Holmes, Light-emitting diodes based on conjugated polymers, Nature. 347 (1990) 539-541. doi:10.1038/347539a0.

[2] N.C. Greenham, S.C. Moratti, D.D.C. Bradley, R.H. Friend, A.B. Holmes, Efficient lightemitting diodes based on polymers with high electron affinities, Nature. 365 (1993) 628630. doi:10.1038/365628a0.

[3] A.W. Grice, D.D.C. Bradley, M.T. Bernius, M. Inbasekaran, W.W. Wu, E.P. Woo, High brightness and efficiency blue light-emitting polymer diodes, Appl. Phys. Lett. 73 (1998) 629. doi:10.1063/1.121878.

[4] K.S. Whitehead, M. Grell, D.D.C. Bradley, M. Jandke, P. Strohriegl, Highly polarized blue electroluminescence from homogeneously aligned films of poly(9,9-dioctylfluorene), Appl. Phys. Lett. 76 (2000) 2946. doi:10.1063/1.126525.

[5] S. Janietz, D.D.C. Bradley, M. Grell, C. Giebeler, M. Inbasekaran, E.P. Woo, Electrochemical determination of the ionization potential and electron affinity of poly(9,9dioctylfluorene), Appl. Phys. Lett. 73 (1998) 2453-2455. doi:10.1063/1.122479.

[6] R.H. Friend, R.W. Gymer, A.B. Holmes, J.H. Burroughes, R.N. Marks, C. Taliani, D.D.C. Bradley, M. Loglund, W.R. Salaneck, D.A. Dos Santos, J.L. Bredas, Electroluminescence in conjugated polymers, Nature. 397 (1999) 121-128. doi:10.1038/16393.

[7] L. Ke, S.J. Chua, K. Zhang, N. Yakovlev, Degradation and failure of organic light-emitting devices, Appl. Phys. Lett. 80 (2002) 2195-2197. doi:10.1063/1.1464216.

[8] D.-Y. Chung, D.-S. Leem, D.D.C. Bradley, A.J. Campbell, Flexible multilayer inverted polymer light-emitting diodes with a gravure contact printed $\mathrm{Cs} 2 \mathrm{CO} 3$ electron injection 
layer, Appl. Phys. Lett. 98 (2011) 103306. doi:10.1063/1.3560484.

[9] P. De Bruyn, D.J.D. Moet, P.W.M. Blom, All-solution processed polymer light-emitting diodes with air stable metal-oxide electrodes, Org. Electron. 13 (2012) 1023-1030. doi:10.1016/j.orgel.2012.02.014.

[10] S.A. Haque, S. Koops, N. Tokmoldin, J.R. Durrant, J. Huang, D.D.C. Bradley, E. Palomares, A multilayered polymer light-emitting diode using a nanocrystalline metaloxide film as a charge-injection electrode, Adv. Mater. 19 (2007) 683-687. doi:10.1002/adma.200601619.

[11] N. Tokmoldin, N. Griffiths, D.D.C. Bradley, S.A. Hague, A hybrid inorganic-organic semiconductor light-emitting diode using $\mathrm{ZrO} 2$ as an electron-injection layer, Adv. Mater. 21 (2009) 3475-3478. doi:10.1002/adma.200802594.

[12] X. Wu, L. Liu, W.C.H. Choy, T. Yu, P. Cai, Y. Gu, Z. Xie, Y. Zhang, L. Du, Y. Mo, S. Xu, Y. Ma, Substantial performance improvement in inverted polymer light-emitting diodes via surface plasmon resonance induced electrode quenching control., ACS Appl. Mater. Interfaces. 6 (2014) 11001-6. doi:10.1021/am5033764.

[13] M. Sessolo, H.J. Bolink, Hybrid organic-inorganic light-emitting diodes., Adv. Mater. 23 (2011) 1829-45. doi:10.1002/adma.201004324.

[14] L.P. Lu, D. Kabra, R.H. Friend, Barium Hydroxide as an Interlayer Between Zinc Oxide and a Luminescent Conjugated Polymer for Light-Emitting Diodes, Adv. Funct. Mater. 22 (2012) 4165-4171. doi:10.1002/adfm.201200850.

[15] H.J. Bolink, H. Brine, E. Coronado, M. Sessolo, Ionically Assisted Charge Injection in Hybrid Organic-Inorganic Light-Emitting Diodes, ACS Appl. Mater. Interfaces. 2 (2010) 2694-2698. doi:10.1021/am1005018. 
[16] J. Sun Park, B. Ram Lee, E. Jeong, H.-J. Lee, J. Min Lee, J.-S. Kim, J. Young Kim, H. Young Woo, S. Ouk Kim, M. Hoon Song, High performance polymer light-emitting diodes with N-type metal oxide/conjugated polyelectrolyte hybrid charge transport layers, Appl. Phys. Lett. 99 (2011) 163305. doi:10.1063/1.3653962.

[17] H. Choi, J.S. Park, E. Jeong, G.-H. Kim, B.R. Lee, S.O. Kim, M.H. Song, H.Y. Woo, J.Y. Kim, Combination of titanium oxide and a conjugated polyelectrolyte for high-performance inverted-type organic optoelectronic devices., Adv. Mater. 23 (2011) 2759-63. doi:10.1002/adma.201100266.

[18] S.-H. Oh, S.-I. Na, Y.-C. Nah, D. Vak, S.-S. Kim, D.-Y. Kim, Novel cationic water-soluble polyfluorene derivatives with ion-transporting side groups for efficient electron injection in PLEDs, Org. Electron. 8 (2007) 773-783. doi:10.1016/j.orgel.2007.06.011.

[19] C. Hoven, R. Yang, A. Garcia, A.J. Heeger, T.-Q. Nguyen, G.C. Bazan, Ion motion in conjugated polyelectrolyte electron transporting layers., J. Am. Chem. Soc. 129 (2007) 10976-7. doi:10.1021/ja072612q.

[20] C. V Hoven, R. Yang, A. Garcia, V. Crockett, A.J. Heeger, G.C. Bazan, T.-Q. Nguyen, Electron injection into organic semiconductor devices from high work function cathodes., Proc. Natl. Acad. Sci. U. S. A. 105 (2008) 12730-5. doi:10.1073/pnas.0806494105.

[21] J.W. Ryan, E. Palomares, E. Martínez-Ferrero, Towards low-temperature preparation of airstable hybrid light-emitting diodes, J. Mater. Chem. 21 (2011) 4774. doi:10.1039/c0jm03636f.

[22] H. Lee, I. Park, J. Kwak, D.Y. Yoon, C. Lee, Improvement of electron injection in inverted bottom-emission blue phosphorescent organic light emitting diodes using zinc oxide nanoparticles, Appl. Phys. Lett. 96 (2010) 153306. doi:10.1063/1.3400224. 
[23] M. Sessolo, H.J. Bolink, H. Brine, H. Prima-Garcia, R. Tena-Zaera, Zinc oxide nanocrystals as electron injecting building blocks for plastic light sources, J. Mater. Chem. 22 (2012) 4916. doi:10.1039/c2jm15584b.

[24] K. Kim, M. Suh, J. Choi, D. Lee, Y. Kim, Conjugated Polyelectrolyte Hybridized ZnO Nanoparticles as a Cathode Interfacial Layer for Effi cient Polymer Light-Emitting Diodes, Adv. Funct. Mater. 25 (2015) 7450-7456. doi:10.1002/adfm.201502360.

[25] M. Jia, X. Xu, J. Peng, J. Zhang, C. Yao, L. Li, Solution-Processed Double-Layer ElectronTransport Layer for Conventional Blue Phosphorescent Organic Light-Emitting Diodes, Adv. Opt. Mater. 4 (2016) 1635-1641. doi:10.1002/adom.201600244.

[26] H.J. Bolink, E. Coronado, D. Repetto, M. Sessolo, E.M. Barea, J. Bisquert, G. GarciaBelmonte, J. Prochazka, L. Kavan, Inverted solution processable OLEDs using a metal oxide as an electron injection contact, Adv. Funct. Mater. 18 (2008) 145-150. doi:10.1002/adfm.200700686.

[27] J.C.D. Faria, A.J. Campbell, M.A. McLachlan, Fluorene copolymer bilayers for emission colour tuning in inverted hybrid light emitting diodes, J. Mater. Chem. C. 3 (2015) 49454953. doi:10.1039/C5TC00263J.

[28] S.H. Oh, S.I. Na, J. Jo, B. Lim, D. Vak, D.Y. Kim, Water-Soluble Polyfluorenes as an Interfacial Layer Leading to Cathode-Independent High Performance of Organic Solar Cells, Adv. Funct. Mater. 20 (2010) 1977-1983. doi:10.1002/adfm.200902386.

[29] K. Zilberberg, A. Behrendt, M. Kraft, U. Scherf, T. Riedl, Ultrathin interlayers of a conjugated polyelectrolyte for low work-function cathodes in efficient inverted organic solar cells, Org. Electron. Physics, Mater. Appl. $14 \quad$ (2013) 951-957. doi:10.1016/j.orgel.2013.01.018. 
[30] B. Lee, W. Lee, T. Nguyen, J.S. Park, J.-S. Kim, J.Y. Kim, H.Y. Woo, S.M. Hoon, Emitting Hybrid Polymer Light-Emitting Diodes via Förster Resonance Energy Transfer Based on Homogeneous Polymer Blends With a Same Polyfluorene Backbone, ACS Appl. Mater. Interfaces. 5 (2013) 5690-5695. doi:10.1021/am401090m.

[31] W.J.E. Beek, M.M. Wienk, R.A.J. Janssen, Efficient hybrid solar cells from zinc oxide nanoparticles and a conjugated polymer, Adv. Mater. 16 (2004) 1009-1013. doi:10.1002/adma.200306659.

[32] W.J.E. Beek, M.M. Wienk, R.A.J. Janssen, Hybrid solar cells from regioregular polythiophene and $\mathrm{ZnO}$ nanoparticles, Adv. Funct. Mater. 16 (2006) 1112-1116. doi:10.1002/adfm.200500573.

[33] C. Giebeler, S.A. Whitelegg, A.J. Campbell, M. Liess, S.J. Martin, P.A. Lane, D.D.C. Bradley, G. Webster, P.L. Burn, Optical studies of electric fields in poly(2-methoxy-5ethyl-hexyloxy) para-phenylene vinylene) light-emitting diodes, Appl. Phys. Lett. 74 (1999) 3714. doi:10.1063/1.123238.

[34] W. Brütting, H. Riel, T. Beierlein, W. Riess, Influence of trapped and interfacial charges in organic multilayer light-emitting devices, J. Appl. Phys. 89 (2001) 1704-1712. doi:10.1063/1.1332088.

[35] A. Rihani, L. Hassine, J.L. Fave, H. Bouchriha, Study of the transient EL slow rise in single layer OLEDs, Org. Electron. 7 (2006) 1-7. doi:10.1016/j.orgel.2005.06.004.

[36] M. Suh, J. Bailey, S.W. Kim, K. Kim, D.-J. Yun, Y. Jung, I. Hamilton, N. Chander, X. Wang, D.D.C. Bradley, D.Y. Jeon, J.-S. Kim, High-Efficiency Polymer LEDs with Fast Response Times Fabricated via Selection of Electron-Injecting Conjugated Polyelectrolyte Backbone Structure, ACS Appl. Mater. Interfaces. 7 (2015) 26566-26571. 
doi:10.1021/acsami.5b07862.

[37] S. Stolz, Y. Zhang, U. Lemmer, G. Hernandez-Sosa, H. Aziz, Degradation mechanisms in organic light-emitting diodes with polyethylenimine as a solution-processed electron injection layer, ACS Appl. Mater. Interfaces. 9 (2017) 2776-2785. doi:10.1021/acsami.6b15062.

[38] A. Garcia, R.C. Bakus, P. Zalar, C. V Hoven, J.Z. Brzezinski, T.-Q. Nguyen, Controlling ion motion in polymer light-emitting diodes containing conjugated polyelectrolyte electron injection layers., J. Am. Chem. Soc. 133 (2011) 2492-8. doi:10.1021/ja106268w.

[39] J. Huang, X. Wang, A.J. DeMello, J.C. DeMello, D.D.C. Bradley, Efficient flexible polymer light emitting diodes with conducting polymer anodes, J. Mater. Chem. 17 (2007) 3551-3554. doi:10.1039/b705918n.

[40] D.Y.Chung, J. Huang, D.D.C. Bradley, A.J. Campbell, High performance, flexible polymer light-emitting diodes (PLEDs) with gravure contact printed hole injection and light emitting layers, Org. Electron. 11 (2010) 1088-1095. doi:10.1016/j.orgel.2010.03.010.

[41] A. Sandström, H.F. Dam, F.C. Krebs, L. Edman, Ambient fabrication of flexible and largearea organic light-emitting devices using slot-die coating, Nat. Commun. 3 (2012) 1002. doi:10.1038/ncomms2002.

[42] D. Kabra, L.P. Lu, M.H. Song, H.J. Snaith, R.H. Friend, Efficient single-layer polymer light-emitting diodes., Adv. Mater. 22 (2010) 3194-8. doi:10.1002/adma.201000317.

[43] B.R. Lee, E.D. Jung, J.S. Park, Y.S. Nam, S.H. Min, B.-S. Kim, K.-M. Lee, J.-R. Jeong, R.H. Friend, J.-S. Kim, S.O. Kim, M.H. Song, Highly efficient inverted polymer lightemitting diodes using surface modifications of ZnO layer., Nat. Commun. 5 (2014) 4840. doi:10.1038/ncomms5840. 
[44] Y. Kim, D.D.C. Bradley, Bright red emission from single layer polymer light-emitting devices based on blends of regioregular P3HT and F8BT, Curr. Appl. Phys. 5 (2005) 222226. doi:10.1016/j.cap.2003.11.090. 